\title{
Kontribusi Planned Happenstance Skills terhadap Perilaku Eksplorasi Karier Siswa Sekolah Menengah Kejuruan: Peran Mediasi Career Decision Self-Efficacy
}

(Planned Happenstance Skills and Career Exploration of Vocational High School Students: The Mediating Role of Career Decision Self-Efficacy)

Subhanallah Ramdhan*, Rose Mini Agoes Salim

Program Magister Sains Pendidikan, Fakultas Psikologi, Universitas Indonesia, Jalan Margonda Raya, Depok, Jawa Barat, 16424 Indonesia

*corresponding author, e-mail: subhanallahr93@gmail.com

Article received: September $13^{\text {th }} 2019$; revised: November $1^{\text {st }} 2019$; accepted: November $2^{\text {nd }} 2019$

\begin{abstract}
Career exploration is the acquisition of career information that results in the formation of career maturity. This study aims to explain the role of internal factors that drive career exploration behavior. Specifically, the study examines the role of career decision self-efficacy in mediating the effect of planned happenstance skills on career exploration behavior. The study applied correlational design with regression analysis. 414 male and 394 female students from vocational high schools in Jakarta were chosen purposively to participate in the study. The Career Exploration Survey, The Planned Happenstance Skill Inventory, and The Career Decision Self-Efficacy Scale-Short Form were used to collect research data. The results show that the effect of planned happenstance skills on student career exploration behavior was partially mediated by career decision self-efficacy. This indicates that the development of the ability to take advantage of certain events can form career related behaviors. Based on the results, it is recommended for school counselors to train students with planned happenstance skills while conducting career counseling in order to develop their career readiness optimally.
\end{abstract}

Keywords: career exploration behaviour; planned happenstance skill; career decision self-efficacy; adolescent; vocational school

\begin{abstract}
Abstrak: Eksplorasi karier adalah perilaku pemerolehan informasi yang berujung pada terbentuknya kematangan karier seseorang. Penelitian ini berusaha menjelaskan peran faktor intriksik yang mendorong perilaku eksplorasi karier siswa. Secara spesifik, penelitian ini menguji peran career decision selfefficacy dalam memediasi pengaruh planned happenstance skill terhadap perilaku eksplorasi karier siswa. Penelitian kuantitatif ini mempunyai desain penelitian korelasional dengan teknik analisis regresi. Pengambilan sampel dilakukan dengan menggunakan teknik purposive sampling. Responden pada penelitian ini adalah para siswa dari Sekolah Menengah Kejuruan (SMK) di Jakarta. Pengambilan data secara survei dilakukan kepada responden yang terdiri dari 414 laki-laki dan 394 perempuan. Alat ukur yang digunakan adalah Career Exploration Survey, The Planned Happenstance Skill Inventory, serta Career Decision Self-Efficacy Scale Short Form. Berdasarkan hasil uji regresi dengan PROCESS dari Hayes, ditemukan bahwa pengaruh yang dihasilkan oleh planned happenstance skill terhadap perilaku eksplorasi karier siswa dimediasi secara parsial oleh career decision self-efficacy. Penelitian ini mengindikasikan bahwa pengembangan terhadap kemampuan mengambil kesempatan dari peristiwa tertentu dapat membantu siswa dalam proses pembentukan perilaku yang terkait karier. Berdasarkan hasil penelitian ini, konselor sekolah disarankan untuk menggabungkan pelatihan kemampuan planned happenstance pada saat sedang melakukan sesi konseling agar kesiapan siswa dalam kariernya bisa berkembang dengan optimal.
\end{abstract}

Kata kunci: perilaku eksplorasi karier; planned happenstance skill; career decision self-efficacy; remaja; SMK 


\section{PENDAHULUAN}

Pembelajaran harus mempunyai tujuan yang terlihat dalam penyediaan desain pembelajaran yang sesuai (Loewenberg Ball \& Forzani, 2009). SMK, memiliki tujuan untuk menyiapkan siswa pada suatu bidang tertentu sesuai dengan yang termaktub dalam Undang-Undang No. 20 Tahun 2003 Pasal 15 (Damarjati, 2016). Keberadaan SMK, dimaksudkan untuk mencetak siswa yang terampil dan mempunyai keterampilan yang mumpuni sebagai bentuk jawaban atas persaingan global yang kian sengit. Hal ini tidak lepas dari karakteristik dari sebuah sekolah kejuruan yang menitikberatkan kesuksesan pada performa yang mumpuni ketika berada di dalam dunia kerja (Damarjati, 2016), yang pada akhirnya akan berujung pada keterserapan siswa dalam dunia kerja.

Berdasarkan data Badan Pusat Statistik tahun 2017-2018, SMK adalah institusi yang memiliki persentase pengangguran paling tinggi $(11,24 \%)$ jika dibandingkan dengan tingkat pendidikan lainnya. Tingginya tingkat pengangguran pada lulusan SMK adalah bukti bahwa ketiadaan daya saing dari lulusan SMK terhadap lulusan pendidikan lainnya (Ngadi, 2014), bahkan hampir separuh lulusan SMK tidak bekerja sesuai dengan bidang yang ia kuasai (Muttaqin et al., 2017). Berdasarkan sebuah survei diketahui bahwa tingginya angka pengangguran lulusan SMK dikarenakan ketidaksuaian kemampuan yang lulusan tekuni di sekolah dengan lapangan tempat mereka bekerja serta ketiadaan wawasan dan informasi yang memadai perihal dunia kerja yang akan dimasuki (Wicaksonoputro \& Indrayanti, 2017).

Perbedaan antara sistem pelatihan dan informasi yang ada di lapangan, membuat siswa membutuhkan pendampingan dari pihak-pihak terkait seperti pihak Bimbingan dan Konseling (BK) di sekolah (Mahir, et al., 2019). Keberadaan pihak BK di sekolah harus mengoklaborasikan pemahaman diri dan pengalaman yang didapatkan siswa serta hubungannya terhadap keberadaan berbagai alternatif pekerjaan di lapangan (Mahir et al., 2019). BK mempunyai tanggung jawab untuk menyediakan informasi terkait kompetensi serta lapangan pekerjaan yang tersedia bagi para siswa (Haq \& Farida, 2019).

Kekurangan wawasan dan informasi terhadap dunia kerja akan menjadi suatu permasalahan dalam proses pencarian dan pengembangan karier seseorang karena berkaitan dengan bagaimana ia dapat mengenali diri atau lingkungan di sekitarnya. Pengenalan terhadap hal apa saja yang dapat digunakan sebagai "kesempatan" dalam menghadapi dunia kerja akan berpengaruh dalam proses memilih karier yang diinginkannya (Modestino et al., 2019). Masa-masa kritis tersebut terutama berada pada masa awal remaja (Santilli et al., 2019), mereka akan dihadapkan pada beberapa keputusan krusial perihal pemilihan karier yang akan digeluti ketika sudah menginjak dewasa seperti dalam aspirasi karier, rencana dan tujuan karier yang akan digeluti, sehingga banyak orang akan mulai mencari informasi dalam keputusan perihal kariernya ketika pada masa remaja (Kolarić et al., 2018).

Proses mengenai bagaimana cara mencari informasi terkait pengembangan karier disebut sebagai sebuah perilaku eksplorasi karier (Greenhaus \& Callanan, 2006). Salah satu bentuk konseling yang paling dibutuhkan bagi para siswa adalah konseling terkait eksplorasi terhadap pekerjaan (Babatunde, 2018). Hal ini juga sesuai dengan penelitian lain yang menunjukkan bahwa para siswa SMK belum bisa memutuskan pekerjaan mereka karena kurangnya informasi terkait pekerjaan, sehingga masih membutuhkan bimbingan dari pihak lain (Haq \& Farida, 2019). Siswa sekolah menengah baik pada tingkatan pertama maupun atas mempunyai kemampuan eksplorasi karier yang rendah dan harus mendapatkan penanganan dan arahan dari konselor sekolah (Silvianingsih et al., 2019).

Perilaku eksplorasi karier adalah sebuah perilaku pemecahan masalah yang dilakukan seseorang untuk memperoleh informasi mengenai diri serta lingkungan di sekitarnya, dalam kaitannya dengan proses memilih, menyiapkan, memasuki, menyesuaikan diri dan mengembangan karier (Jordaan, 1963). Perilaku eksplorasi karier adalah perilaku dan kognisi yang dilakukan seseorang untuk menggali informasi mengenai pekerjaannya (Stumpf et al., 1983). Definisi tersebut kemudian lebih diperjelas oleh Zikic \& Klehe, (2006) yang menyatakan bahwa perilaku eksplorasi karier adalah sebuah pengumpulan terhadap informasi terkait pengembangan karier seseorang.

Perilaku eksplorasi karier adalah prediktor terbentuknya kongruensi pada diri seseorang. Jika dihubungkan dengan teori pemilihan pekerjaan yang menyebutkan diperlukannya sebuah keseimbangan antara diri seseorang dengan lingkungan dalam proses pemilihan pekerjaan dan karier, eksplorasi karier memegang peran penting dalam penentuan seseorang dalam memilih pekerjaannya (Chan, 2018; 
Modestino et al., 2019; Zikic \& Hall, 2009). Perilaku eksplorasi karier juga akan membentuk sikap (Jiang et al., 2019), merencanakan karier di masa mendatang (Demulier et al., 2013), dan mematangkan karier yang dimiliki seseorang (Lau et al., 2019).

Pada proses eksplorasi karier, terjadi pemerolehan informasi karier serta pengujian terhadap hipotesis baik terhadap diri maupun lingkungan guna untuk mencapai tujuan yang diinginkan (Hall, 1986), sehingga perilaku eksplorasi karier juga tidak akan lepas dengan aspek di luar diri manusia seperti sosial dan budaya sekitar (Greenhaus \& Callanan, 2006). Jiang et al., (2019) menambahkan bahwa aspek-aspek internal diri, seperti berbagai variabel demografis, nilai dan kemampuan spesifik yang dimiliki seseorang akan sangat berperan penting dalam pembentukan perilaku eksplorasi karier, bahkan termasuk juga emosi di dalamnya, sehingga seseorang dapat menilai apakah ia cocok atau tidak dengan lingkungan tempat ia bekerja (Kidd, 1998).

Berkenaan dengan kemampuan individu, berdasarkan pengalaman yang telah seseorang dapatkan sebelumnya, ia dapat mengembangkan kemampuan untuk bersiap menghadapi dan mengembangkan kejadian tidak terduga menjadi sebuah kesempatan baginya (Krumboltz, 2009; Mitchell et al., 1999). Pada Planned Happenstance Theory, terdapat dua konsep utama yang berkaitan dengan hal tersebut, yaitu: (1) pengembangan terhadap berbagai kesempatan yang dapat meningkatkan kepuasan dalam hidup, serta (2) adanya kemampuan yang memungkinkan untuk meraih kesempatan tersebut. Berdasarkan hal ini, maka kemampuan seseorang untuk mengenali, membuat dan menggunakan kejadian tidak terduga sebagai kesempatan yang menguntungkan disebut PHS (Krumboltz, 2009; Krumboltz et al., 2013; Mitchell et al., 1999).

Seseorang yang mempunyai kemampuan untuk menjadikan kejadian tidak terduga menjadi kesempatan akan dapat melakukan eksplorasi karier dengan baik. Kejadian tidak terduga dapat dianggap sebagai penghalang bagi seseorang untuk melakukan eksplorasi dalam kariernya, karena ia tidak terikat oleh usia tertentu atau seberapa banyak proses eksplorasi yang telah dilakukan seseorang (Zikic \& Hall, 2009). Untuk mengatasi kejadian-kejadian tidak terduga dan mengubahnya menjadi kesempatan yang menguntungkan bagi diri seseorang, diperlukan sebuah strategi (Pryor \& Bright, 2014). Beberapa teori menyebutkan bahwa untuk menghasilkan sebuah eksplorasi karier diperlukan perencanaan dan kesempatan yang disediakan oleh lingkungan seperti yang dijelaskan pada Planned Happenstance Theory (Mitchell et al., 1999; Zikic \& Hall, 2009). PHS akan berkembang ketika seseorang berada pada masa transisi di antara sekolah dan masa kerja (Yang et al., 2017).

Hubungan antara $P H S$ dengan eksplorasi karier secara umum belum tergambar secara kuat dalam beberapa penelitian empirik. Pemahaman mengenai hubungan keduanya "hanya" dapat dilihat pada penelitian yang dilakukan oleh Hwang et al., (2012) yang menunjukkan bahwa terdapat hubungan positif antara $P H S$ dengan eksplorasi karier, dengan nilai kontribusi sebesar 0,19 . Kontribusi ini cenderung kecil, sehingga dibutuhkan sebuah penelitian lanjut dengan pembuatan model yang berbeda di dalamnya.

Pada berbagai penelitian mengenai eksplorasi karier, career decision self-efficacy (CDSE) adalah aspek yang tidak terpisahkan dan dapat disebutkan bahwa CDSE adalah salah satu faktor kunci dalam pengembangan ekplorasi karier seseorang (Jiang, 2015). CDSE adalah keyakinan yang dimiliki seseorang untuk menyelesaikan sebuah tugas yang diperlukan dalam proses memutuskan karier (Betz et al., 1996). Seseorang dengan kepercayaan diri tinggi, cenderung melakukan perilaku eksplorasi karier secara lebih aktif. CDSE adalah penghubung di antara aspek karakteristik individu dengan perilaku karier yang ditampakkan (Brown \& Lent, 2019). Keberadaan CDSE dalam diri seseorang akan meningkatkan kepercayaan dirinya sehingga ia bisa secara tepat memilih tujuan dan menjaga komitmen terhadap karier yang telah dipilihnya. Beberapa penelitian menunjukkan pengaruh $C D S E$ yang signifikan terhadap perilaku eksplorasi karier seseorang (An \& Lee, 2017; Cheung \& Arnold, 2014; Gamboa et al., 2013).

Pada berbagai penelitian menyebutkan bahwa $P H S$ mempunyai hubungan erat terhadap terbentuknya CDSE pada diri seseorang (Boram Kim et al., 2014; Boyoung Kim et al., 2018). Peningkatan kemampuan seseorang untuk merencanakan kemungkinan yang tidak terduga menjadi sebuah kesempatan dapat meningkatkan keyakinannya dalam sebuah perilaku tertentu. Secara teoretis, $P H S$ juga akan mempunyai hubungan yang saling terkait dengan CDSE. Hal ini dikarenakan keberfungsiannya untuk mendorong seseorang agar dapat berperilaku secara fleksibel ketika berada dalam situasi yang berbeda. Selain itu, seseorang yang bisa menggunakan happenstance dengan baik dapat menjadikan kesempatan tersebut agar menguntungkan bagi dirinya (Kim et al., 2014; Mitchell et al., 1999). 
Jika menutut teori Social Cognitive Career Theory (SCCT) yang menyebutkan bahwa CDSE adalah poin utama dalam proses pembelajaran manusia (Brown \& Lent, 2019; Yang et al., 2017), CDSE akan memfasilitasi pengalaman seseorang agar terwujud dalam suatu perilaku tertentu. PHS sebagai hasil pengalaman manusia akan menjadi sebuah bentuk perilaku eksplorasi karier dengan melalui keberadaan CDSE di dalamnya.

Berdasarkan pemaparan dalam paragraf sebelumnya, peneliti mengajukan dua hipotesis awal yaitu mengenai ada tidaknya pengaruh dari $P H S$ dan $C D S E$ terhadap perilaku eksplorasi karier siswa. Peneliti juga ingin melihat kontribusi secara mediasi dari CDSE terhadap perilaku eksplorasi karier siswa SMK. Hasil dari penelitian ini diharapkan dapat menjadi sebuah panduan bagi konselor sekolah dalam proses pemberian informasi terhadap siswa untuk menghadapi berbagai perubahan dalam dunia kerja, sehingga siswa dapat mempersiapkan diri dengan baik.

\section{METODE}

Penelitian ini adalah penelitian kuantitatif non-eksperimental dengan desain korelasional karena bertujuan untuk mengetahui hubungan antar variabel yang diujikan. Sesuai dengan pemahaman yang disampaikan oleh Cozby \& Bates, (2015), peneliti melakukan proses pemilihan responden atau sampling secara purposive kepada siswa SMK yang sesuai kriteria. Responden pada penelitian ini adalah 808 siswa SMK di Jakarta. Responden terdiri dari 414 laki-laki (51,2\%) dan 394 siswa perempuan (48,8\%) yang berada dalam rentang usia 16-18 tahun.

Pengambilan data dilakukan dengan melakukan penyebaran tiga kuesioner yang berisi butirbutir dari tiga alat ukur yang digunakan dalam penelitian ini. Ketiga alat ukur yang digunakan telah dialihbahasakan ke dalam bahasa indonesia oleh peneliti sebelumnya, sehingga dalam prosesnya peneliti hanya melakukan proses perizinan kepada peneliti sebelumnya. Ketiga alat ukur yang digunakan adalah adalah: Career Exploration Survey (CES); The Planned Happenstance Skill Inventory (PHCI); dan Career Decision Self-Efficacy Scale Short Form (CDSE-SF).

$C E S$ oleh Stumpf et al., (1983) untuk mengukur variabel eksplorasi karier. CES yang digunakan dalam penelitian ini diperoleh dari Preston, (2018) yang telah melakukan adaptasi dan expert judgement, sedangkan untuk uji reliabilitas menggunakan Alpha Cronbach yang mempunyai nilai 0,834 $>0,7$ atau dikategorikan sebagai high reliability (Hinton et al., 2014). Kuesioner tersebut terdiri dari 15 butir pernyataan, yang berisi tiga dimensi utama yaitu proses eksplorasi, reaksi terhadap eksplorasi serta kepercayaan. Pada kuesioner tersebut salah satu contoh butir pernyataannya berbunyi "Menyelidiki berbagai pilihan karier yang ada". Kuesioner tersebut berbentuk Skala Likert yang mempunyai rentang jawaban 1 "tidak pernah" sampai 5 "selalu", dimana semakin tinggi jawaban semakin tinggi pula tingkat eksplorasi karier seseorang.

PHCI yang digunakan untuk mengukur kemampuan planned happenstance dikembangkan oleh Kim et al., (2014) berdasar teori Krumboltz, (2009). Pada penelitian ini alat ukur yang digunakan berdasarkan hasil adaptasi yang dilakukan oleh Sofyan \& Indianti, (2019). Uji validitas yang dilakukan menggunakan penilaian expert, dan untuk uji reliabilitas menggunakan nilai Alpha Cronbach yang mempunyai nilai $0,895>0,7$ atau dikategorikan sebagai high reliability (Hinton et al., 2014). Kuesioner mempunyai 25 butir pernyataan yang mengukur lima aspek utama yaitu rasa ingin tahu, persistensi, fleksibilitas, optimisme dan risk-taking. Salah satu butir pernyataan dari kuesioner tersebut adalah "Karier masa depan saya cerah". Kuesioner tersebut berbentuk Skala Likert dengan rentang 1 "sangat tidak setuju" sampai 5 "sangat setuju", dimana skor yang semakin tinggi akan semakin mewakili variabel kemampuan planned happenstance.

CDSE-SF dikembangkan oleh Betz et al., (1996) yang kemudian diadaptasi oleh Sawitri, (2008). Alat ini mengukur lima kompetensi,yaitu: penilaian diri yang akurat, pengumpulan informasi pekerjaan, penyeleksian terhadap tujuan, pembuatan rencana masa depan, serta pemecahan masalah. Salah satu bentuk dari butir pernyataan pada kuesioner tersebut adalah "Membuat rencana untuk mencapai cita-cita saya dalam 5 tahun yang akan datang". Pengujian validitas dilakukan dengan menggunakan penilaian expert, sedangkan uji reliabilitas menggunakan nilai Alpha Cronbach dan mempunyai nilai 0,763>0,7 atau dikategorikan sebagai high reliability (Hinton et al., 2014). Kuesioner tersebut berjumlah 25 butir pernyataan dan berbentuk Skala Likert dengan rentang 1-6 yaitu "sangat tidak yakin" sampai "sangat yakin", dimana semakin tinggi skor akan lebih mewakili variabel yang akan diukur. 
Proses analisis data yang diperoleh dari kuesioner $C E S, P H C I$ dan $C D S E-S F$, dilakukan dengan menggunakan uji statistik deskriptif untuk mengetahui rerata setiap variabel, kemudian diujikan secara korelatif menggunakan teknik Pearson Correlation. Selain itu dilakukan pula uji regresi dengan menggunakan PROCESS pada software SPSS 23.0 untuk menguji model mediasi berdasarkan pendapat yang disampaikan Hayes, (2017). Analisis data yang dilakukan bertujuan untuk melakukan uji terhadap hipotesis yang diajukan.

\section{HASIL}

Hasil dari uji korelasional yang dilakukan pada ketiga variabel menunjukkan bahwa terdapat hubungan yang signifikan di antara ketiganya, dapat diketahui bahwa ketiga variabel tersebut saling berhubungan antara satu dengan yang lainnya. Hubungan tersebut disajikan pada tabel 1 , tanda ** menunjukkan $\mathrm{p}<0,001$.

Jika dilihat dari tabel 1 , PHS dan CDSE mempunyai hubungan yang positif dan signifikan dengan perilaku eksplorasi karier siswa SMK. Hubungan antara perilaku eksplorasi karier siswa SMK mempunyai nilai sebesar 0,383 ketika dihubungkan dengan $P H S$ dan nilai 0,348 ketika bersinggungan dengan $C D S E$. Hasil ini menggambarkan bahwa jika terjadi peningkatan nilai pada variabel $P H S$ ataupun $C D S E$, maka akan terjadi peningkatan pula pada nilai perilaku eksplorasi karier.

Untuk memastikan hubungan ketiga variabel tersebut, peneliti melakukan uji regresi berganda, dan didapatkan hasil bahwa PHS dan CDSE mempunyai nilai $R$ square sebesar $0,187(\mathrm{p}<0,001)$ ketika diuji secara simultan kepada variabel perilaku eksplorasi karier siswa SMK. Hasil ini menunjukkan bahwa keduanya mempunyai kontribusi sebesar $18 \%$ dalam memengaruhi keberadaan perilaku eksplorasi karier siswa SMK, seperti yang disajikan pada tabel 2. Tanda ** pada tabel 2 menunjukkan bahwa $\mathrm{p}<$ 0,001 .

Hasil pengujian hipotesis kedua terhadap ketiga variabel yang diajukan mengenai adanya model mediasi dan peran $C D S E$ yang memediasi hubungan antara $P H S$ dan perilaku eksplorasi karier siswa SMK disajikan pada gambar 1 . Tanda ** menunjukkan bahwa $\mathrm{p}<0,001$. Gambar 1 menunjukkan bahwa PHS mempunyai peran dalam membentuk CDSE dengan nilai sebesar 0,483 (p < 0,001), sedangkan $C D S E$ dapat membentuk perilaku eksplorasi karier siswa dengan nilai sebesar $0,285(\mathrm{p}<0,001)$. Hasil ini menunjukkan bahwa $P H S$ mempunyai kontribusi secara positif dan signifikan dalam membentuk $C D S E$ seorang siswa, begitu pula CDSE dapat memberikan pengaruh terhadap perilaku eksplorasi karier siswa, sehingga dapat diketahui bahwa ketiganya mempunyai hubungan yang signifikan antara satu sama lainnya. Gambar 1. juga menunjukkan pengaruh $P H S$ terhadap perilaku eksplorasi karier siswa jika dihubungkan secara langsung adalah $0,387(\mathrm{p}<0,001)$, sedangkan jika tidak langsung dan melalui $C D S E$ nilai pengaruh koefisian antara keduanya adalah sebesar $0,138(\mathrm{p}<0,001)$. Pada hasil tersebut diketahui bahwa pada dasarnya $C D S E$ dapat memediasi pengaruh yang ditimbulkan oleh $P H S$ terhadap perilaku eksplorasi karier siswa, akan tetapi hanya secara parsial saja, hal tersebut dapat dilihat dari penurunan nilai koefisiensi yang terjadi ketika variabel $P H S$ dan perilaku eksplorasi karier dihubungkan

Tabel 1. Hasil Uji Korelasi PHS, CDSE dan Perilaku Eksplorasi Karier

\begin{tabular}{lccccc}
\hline \multicolumn{1}{c}{ Variabel } & M & SD & $\mathbf{1}$ & $\mathbf{2}$ & $\mathbf{3}$ \\
\hline Perilaku Eksplorasi Karier & 3,262 & 0,560 & - & & \\
PHS & 4,012 & 0,414 & $0,383^{* *}$ & - & \\
CDSE & 4,982 & 0,434 & $0,348^{* *}$ & $0,466^{* *}$ & - \\
\hline
\end{tabular}

Tabel 2. Hasil Uji Regresi Berganda Pada PHS, CDSE dan Perilaku Eksplorasi Karier

\begin{tabular}{lccc}
\hline \multicolumn{1}{c}{ Variabel } & $\boldsymbol{R}$ & $\boldsymbol{R}^{2}$ & Standarized Beta \\
\hline Perilaku Eksplorasi Karier & 0,43 & $0,18^{* *}$ & \\
PHS & & & $0,28^{* *}$ \\
CDSE & & & $0,22 * *$ \\
\hline
\end{tabular}




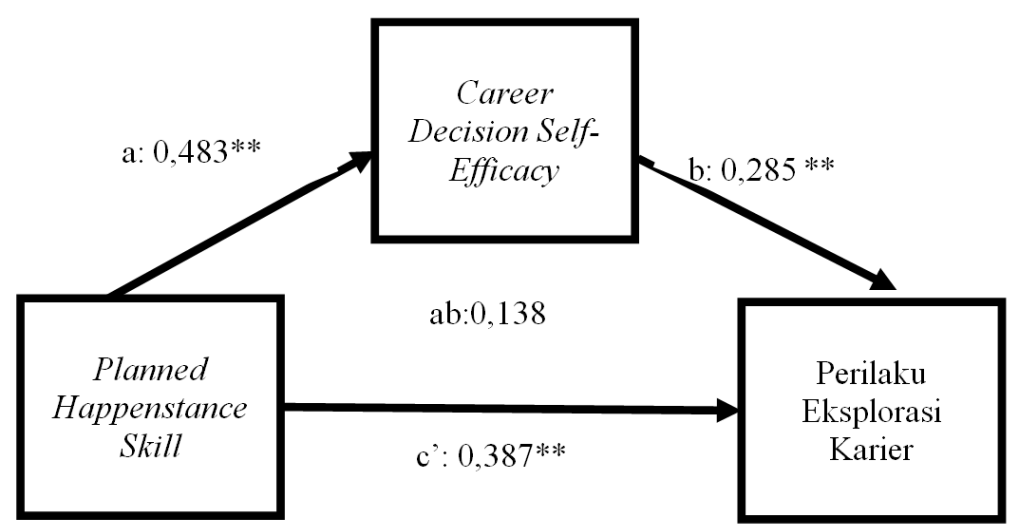

Gambar 1. Diagram Model Mediasi PHS, CDSE dan Perilaku Eksplorasi Karier

secara langsung dan ketika harus melalui variabel mediator. Hasil ini mengindikasikan bahwa walaupun $C D S E$ adalah salah satu mediator di antara kedua variabel yang diujikan, masih ada variabel lain yang dapat menjadi mediator.

\section{PEMBAHASAN}

Siswa SMK yang masih tergolong pada kategori remaja mempunyai tugas perkembangan yang berkenaan dengan identitas karier, seperti melakukan perencanaan ataupun eksplorasi terhadap berbagai kemungkinan karier yang akan dikerjakannya (Erikson, 1963). Seorang siswa harus memulai mengeksplorasi kariernya sedini mungkin ketika mereka berada di sekolah menengah (Knight, 2015), tujuannya adalah agar ia bisa menyiapkan diri, mengetahui kemungkinan dan kesempatan serta agar dapat beradaptasi pada keadaan yang tidak terduga (Kanten et al., 2016).

Hasil yang ditemukan pada penelitian ini pada dasarnya mendukung konsep model self-management pada teori SCCT. Di dalamnya terdapat domain person yang memuat berbagai karakteristik individu memiliki prestasi dan kebahagiaan hidup yang lebih tinggi, termasuk di dalamnya adalah PHS (Brown \& Lent, 2019; Krumboltz et al., 2013). Hal tersebut didukung dengan berbagai penelitian terdahulu yang menyebutkan bahwa $P H S$ akan mendahului terjadinya perilaku terkait karier seperti eksplorasi dan pencarian karier (Brown \& Lent, 2019; Lent et al., 2017). Berbagai temuan lainnya mengatakan bahwa PHS akan berhubungan dengan perilaku karier yang efektif bagi seseorang seperti akan memunculkan motivasi intrinsik untuk melakukan networking (Eissenstat \& Nadermann, 2019), serta kemampuan untuk beradaptasi terhadap kesulitan dalam pekerjaan (Kim et al., 2018), bahkan dalam keadaan kacau sekalipun, sehingga ia cenderung memiliki prestasi dan kebahagiaan hidup yang lebih tinggi (Valickas et al., 2019).

Pada model self-management dari teori SCCT, selain komponen person disebutkan juga bahwa perihal tiga komponen kognitif yaitu keyakinan akan efikasi diri (self-efficacy belief), ekspektasi hasil dan sebuah tujuan yang sangat penting dalam pembentukan perilaku eksplorasi karier merupakan salah satu bentuk perilaku terkait karier (Brown \& Lent, 2019). Efikasi diri dan ekspektasi akan hasil memegang peran penting dalam perilaku eksplorasi karier seseorang, karena ia akan memunculkan perilaku karier yang lebih aktif sehingga proses pengembangan karier akan lebih optimal (Greenhaus \& Callanan, 2006). Hal ini sesuai dengan sebuah penelitian yang menunjukkan bahwa eksplorasi karier dan pengambilan keputusan sangat bergantung pada efikasi diri dan ekspektasi seseorang akan hasil yang akan diperolehnya (Lent et al., 2017).

Hasil yang ditemukan pada penelitian ini juga mendukung berbagai temuan terdahulu yang menunjukkan bahwa terdapat hubungan positif antara CDSE dengan eksplorasi karier seseorang (Chan, 2018; Rogers \& Creed, 2011). Seseorang yang memiliki kepercayaan diri terhadap pilihan kariernya akan memiliki kecenderungan untuk lebih peka dalam melakukan aktivitas eksplorasi karier yang lebih baik (Brown \& Lent, 2019; El-Hassan \& Ghalayini, 2019). Kepercayaan diri dan eksplorasi yang dimiliki seseorang tersebut akan berkembang seiring usia dan pengalaman yang dilalui (Porfeli \& Lee, 2012).

Hasil hipotesa kedua adalah bahwa terdapat peran mediasi CDSE dalam hubungan $P H S$ dengan perilaku eksplorasi karier seseorang secara parsial. Pada berbagai penelitian terdahulu diketahui bahwa $C D S E$ dapat berhubungan langsung, menjadi mediator ataupun moderator terhadap perilaku yang 
berhubungan dengan karier seperti eksplorasi karier (Brown \& Lent, 2019; Zhang \& Huang, 2018). Hal ini menunjukkan bahwa CDSE mempunyai peran yang penting dalam pembentukan perilaku eksplorasi karier seseorang (Ireland \& Lent, 2018).

Peran mediasi yang diambil oleh $C D S E$ juga dibuktikan dalam penelitian yang dilakukan oleh Kim et al., (2014) yang menyatakan bahwa jika seseorang ingin mempunyai efikasi diri yang tinggi terhadap keputusan kariernya, ia harus memiliki kemampuan untuk bisa menghadapi berbagai kemungkinan tidak terduga yang akan datang kepadanya, seperti pada hasil yang disampaikan oleh Sofyan \& Indianti, (2019) yang menemukan hubungan positif dan signifikan antara CDSE dengan PHS. Berbagai karakteristik individual seperti efikasi diri dan kemampuan ini pada akhirnya akan meningkatkan keterlibatan seseorang dalam perilaku kariernya (Brown \& Lent, 2019).

Hasil penelitian menunjukkan bahwa peran yang terjalin adalah mediasi secara parsial, dalam artian bahwa pada dasarnya pengaruh langsung antara $P H S$ dengan perilaku eksplorasi karier lebih tinggi dibandingkan jika menggunakan model mediasi dengan adanya CDSE, hal tersebut telah dibuktikan dalam penelitian empirik yang menunjukkan hubungan langsung antara $P H S$ dengan perilaku eksplorasi karier seseorang (Ahn et al., 2015; Hwang et al., 2012). Hasil tersebut juga mengindikasikan bahwa pada siswa SMK, pengembangan terhadap PHS lebih dapat meningkatkan munculnya perilaku eksplorasi karier daripada dengan adanya $C D S E$. Hal ini dapat dilatarbelakangi kondisi responden yang merupakan seorang remaja. PHS akan sangat mempunyai peranan dalam kehidupan karier seorang remaja yang merupakan masa transisi dari sekolah ke dunia kerja dibandingkan ketika mereka berada pada masa lainnya (Krumboltz et al., 2013). Hal ini dikarenakan pada masa remaja, seseorang akan mengoptimalkan proses pembelajarannya mengenai hal apa saja yang sesuai dan apa saja yang dapat menjadikannya sukses di kemudian hari. Seorang remaja yang berada pada masa transisi akan cenderung merasa tertantang pada hal-hal yang baru diketahuinya, dan PHS akan berkembang dengan pesat dan baik ketika dihadapkan dengan tantangan tersebut (Krumboltz et al., 2013). Pada siswa SMK, pengembangan terhadap kemampuan-kemampuan khusus yang terkait karier lebih dapat memberikan efek daripada pengembangan dalam keyakinan mereka saja. Hal ini dikarenakan keberadaan PHS akan menuntun mereka untuk mempersiapkan diri sebaik mungkin terhadap berbagai kemungkinan di lapangan (Kanten et al., 2016), sehingga akan terjadi sebuah pengembangan karier secara positif (Urbanaviciute et al., 2019).

Seseorang cenderung mempunyai $C D S E$ yang lebih tinggi ketika ia telah mempunyai kemampuan dalam dirinya dan melihat dirinya mempunyai kapabilitas dalam mengontrol keadaan terkait karier yang akan dihadapinya (Nota et al., 2014). Meskipun telah dilatih sesuai dengan penjurusan masing-masing serta diberikan kesempatan magang, para lulusan SMK cenderung tetap mempunyai keterbatasan dalam pengalaman dan pengetahuan perihal dunia kerjanya, hal tersebut tidak lepas dari karakteristik mereka sebagai seorang remaja yang kepercayaan dirinya cenderung tidak stabil (Porfeli \& Lee, 2012). Kepercayaan diri tersebut akan berkembang seiring waktu dan pengalaman keberhasilan yang dilaluinya, sedangkan $P H S$ yang berfokus pada penyediaan kemampuan untuk bersedia terhadap setiap kesempatan akan membantu seseorang meninggikan efikasi dirinya dengan adanya kans keberhasilan yang akan di dapatkannya (Krumboltz et al., 2013).

Hasil yang didapatkan dalam penelitian ini ditemukan bahwa $P H S$ mempunyai pengaruh yang lebih besar terhadap munculnya perilaku eksplorasi karier siswa SMK dibandingkan melalui mediasi CDSE. Hal ini dapat dijadikan bahan pertimbangan konselor sekolah dalam proses pengembangan pembelajaran siswa, terutama siswa SMK yang pada dasarnya berorientasi pada masuknya mereka dalam dunia kerja. Pengembangan $P H S$ dapat dilakukan dengan memberikan informasi dan pengetahuan praktikal mengenai berbagai kemungkinan yang akan diterima oleh siswa pada proses pencarian dan kematangan dalam dunia kerja, sehingga tujuan dari pemunculan perilaku terkait karier bisa terwujud (Krumboltz, 2013). Pengembangan PHS harus diintegrasikan dalam proses konseling (Mitchell et al., 1999). Proses konseling yang berbasis pengembangan kemampuan ini akan berujung pada tereduksinya kecemasan siswa terhadap ketakutan akan masa depan mereka, selain itu kemampuan ini akan mendorong rasa ingin tahu siswa dalam proses pembelajaran serta kesiapannya terhadap berbagai kemungkinan yang akan terjadi dalam pekerjaan mereka.

Penelitian ini kurang bisa menjelaskan kompleksitas dari pemahaman mengenai perilaku terkait karier seperti perilaku eksplorasi karier. Secara umum, perilaku karier bisa dijelaskan dengan SSCT melalui dua model, yang mempunyai fokus berbeda (Brown \& Lent, 2019). Hal ini mengindikasikan 
bahwa penelitian empirik mengenai karier dan bagaimana hubungan antara variabel di dalamnya sangatlah kompleks dan saling berkaitan satu sama lainnya. Maka penelitian selanjutnya diharapkan dapat memperluas cakupan yang cukup jarang disentuh oleh peneliti seperti pada domain person dalam model self-management terutama kaitannya dalam kemampuan-kemampuan spesifik yang dimiliki manusia terhadap perilaku nyata yang dilakukan seseorang terkait kariernya.

\section{SIMPULAN}

Terdapat hubungan positif dan signifikan antara $P H S, C D S E$ dan perilaku eksplorasi karier siswa SMK. Pengaruh mediasi yang dihasilkan oleh $C D S E$ dalam pengaruh $P H S$ terhadap perilaku eksplorasi karier adalah parsial. Hal ini mengindikasian bahwa perilaku eksplorasi karier siswa SMK tidak hanya akan dipengaruhi oleh keyakinan diri, namun juga oleh variabel lain yang tidak ditangkap dalam model penelitian ini, sehingga diperlukan sebuah penelitian lanjutan yang melibatkan berbagai variabel lain atau diteliti dengan sudut pandang lain pada teori SSCT. Karakteristik kurangnya pengalaman pada masa remaja dapat menjadi alasan kurang berpengaruhnya CDSE sebagai mediator pada penelitian ini. Hal ini juga memberikan pandangan bagi pihak BK untuk lebih mematangkan siswa dalam proses pemilihan karier siswa SMK dengan pemberian berbagai informasi alternatif yang berkaitan dengan lapangan pekerjaan yang akan dihadapi serta layanan konseling PHS agar siswa mengembangkan kesiapan menghadapi berbagai kemungkinan, sehingga mereka bisa memilih dan bertahan dalam pilihan kariernya.

\section{DAFTAR RUJUKAN}

Ahn, S., Jung, S. H., Jang, S. H., Du, X., Lee, B. H., Rhee, E., ... Lee, S. M. (2015). Planned happenstance skills and occupational identity status in high school students. The Career Development Quarterly, 63(1), 31-43.

An, H., \& Lee, S.-H. (2017). Career exploration behavior of Korean medical students. Korean Journal of Medical Education, 29(3), 175-185. https://doi.org/10.3946/kjme.2017.63

Babatunde, J. O. (2018). Effectiveness of guidance and counselling strategies at promoting career decision making among youths in Nigeria. International Research Journals, 9(5), 151-156.

Betz, N. E., Klein, K. L., \& Taylor, K. M. (1996). Evaluation of a Short Form of the Career Decision-Making SelfEfficacy Scale. Journal of Career Assessment, 4(1), 47-57. https://doi.org/10.1177/106907279600400103

Brown, S. D., \& Lent, R. W. (2019). Social Cognitive Career Theory at 25: Progress in studying the domain satisfaction and career self-management models. Journal of Career Assessment, 27(4), 563-578. https://doi. org $/ 10.1177 / 1069072719852736$

Chan, C.-C. (2018). The relationship among social support, career self-efficacy, career exploration, and career choices of Taiwanese college athletes. Journal of Hospitality, Leisure, Sport \& Tourism Education, 22, 105109. https://doi.org/10.1016/j.jhlste.2017.09.004

Cheung, R., \& Arnold, J. (2014). The impact of career exploration on career development among Hong Kong Chinese University students. Journal of College Student Development, 55(7), 732-748. https://doi. org $/ 10.1353 / \mathrm{csd} .2014 .0067$

Cozby, P. C., \& Bates, S. C. (2015). Methods in behavioral research. New York: McGraw-Hill.

Damarjati, T. (2016). Konsep pembelajaran di sekolah menengah kejuruan. kementerian pendidikan dan kebudayaan. Retrieved from http://psmk.kemdikbud.go.id/konten/1869/konsep-pembelajaran-di-sekolahmenengah-kejuruan

Demulier, V., Le Scanff, C., \& Stephan, Y. (2013). Psychological predictors of career planning among active elite athletes: An application of the social cognitive career theory. Journal of Applied Sport Psychology, 25(3), 341-353.

Eissenstat, S. J., \& Nadermann, K. (2019). Examining the use of planned happenstance with students of Korean cultural backgrounds in the United States. Journal of Career Development, 46(4), 455-468.

El-Hassan, K., \& Ghalayini, N. (2019). Parental attachment bonds, dysfunctional career thoughts and career exploration as predictors of career decision-making self-efficacy of Grade 11 students. British Journal of Guidance \& Counselling, https://doi.org/10.1080/03069885.2019.1645296.

Erikson, E. H. (1963). Youth: Change and challenge. Basic books.

Gamboa, V., Paixão, M. P., \& de Jesus, S. N. (2013). Internship quality predicts career exploration of high school students. Journal of Vocational Behavior, 83(1), 78-87. 
Greenhaus, J. H., \& Callanan, G. A. (2006). Encyclopedia of career development. California: SAGE Publications Inc.

Hall, D. T. (1986). Breaking career routines: Midcareer choice and identity development. Career Development in Organizations, 120-159.

Haq, A. H. B., \& Farida, R. (2019). Orientasi karir pada siswa SMP: Pilihan jurusan dan gambaran Pekerjaan di masa depan. Psikostudia: Jurnal Psikologi, 8(1), 7-14.

Hayes, A. F. (2017). Introduction to mediation, moderation, and conditional process analysis: A regression-based approach. Guilford publications.

Hinton, P. R., McMurray, I., \& Brownlow, C. (2014). SPSS explained. Routledge.

Hwang, H., Jang, S., Chung, S., \& Lee, S. (2012). Examining the relationship of career aspiration and job exploration behavior on the level of planned happenstance skills. The Korea Journal of Youth Counseling, 20(2), 193-210.

Ireland, G. W., \& Lent, R. W. (2018). Career exploration and decision-making learning experiences: A test of the career self-management model. Journal of Vocational Behavior, 106, 37-47.

Jiang, Z. (2015). Core self-evaluation and career decision self-efficacy: A mediation model of value orientations. Personality and Individual Differences, 86, 450-454. https://doi.org/10.1016/j.paid.2015.07.012

Jiang, Z., Newman, A., Le, H., Presbitero, A., \& Zheng, C. (2019). Career exploration: A review and future research agenda. Journal of Vocational Behavior, 110, 338-356. https://doi.org/10.1016/j.jvb.2018.08.008

Jordaan, J. P. (1963). Exploratory behavior: The formation of self and occupational concepts. Career Development: Self-Concept Theory, 42-78.

Kanten, S., Kanten, P., \& Yeşiltaş, M. (2016). The role of career self-efficacy on the effect of parental career behaviors on career exploration: A study on school of tourism and hotel management'students. European Journal of Multidisciplinary Studies, 1(6), 143-154.

Kidd, J. M. (1998). Emotion: An absent presence in career theory. Journal of Vocational Behavior, 52(3), $275-288$.

Kim, Boram, Jang, S. H., Jung, S. H., Lee, B. H., Puig, A., \& Lee, S. M. (2014). A moderated mediation model of planned happenstance skills, career engagement, career decision self-efficacy, and career decision certainty. The Career Development Quarterly, 62(1), 56-69. https://doi.org/10.1002/j.2161-0045.2014.00070.x

Kim, Boyoung, Kim, S. R., Yang, N. Y., Yaung, H., Ha, G. Y., Yang, J. Y., ... Lee, S. M. (2018). Longitudinal relationships between planned happenstance skills and life adjustment and the moderating role of career barriers. Journal of Career Development, 45(3), 215-226. https://doi.org/10.1177/0894845316681078

Knight, J. L. (2015). Preparing elementary school counselors to promote career development: Recommendations for school counselor education programs. Journal of Career Development, 42(2), 75-85.

Kolarić, A., Cool, C., \& Stričević, I. (2018). Adolescent information behaviour in everyday life decision making. Vjesnik Bibliotekara Hrvatske, 61(1), 83-125.

Krumboltz, J. D. (2009). The happenstance learning theory. Journal of Career Assessment, 17(2), 135-154. https:// doi.org/10.1177/1069072708328861

Krumboltz, J. D., Foley, P. F., \& Cotter, E. W. (2013). Applying the happenstance learning theory to involuntary career transitions. The Career Development Quarterly, 61(1), 15-26. https://doi.org/10.1002/j.21610045.2013.00032.x

Lau, P. L., Chung, Y. B., \& Wang, L. (2019). Effects of a career exploration intervention on students' career maturity and self-concept. Journal of Career Development, 1-14. https://doi.org/10.1177/0894845319853385

Lent, R. W., Ireland, G. W., Penn, L. T., Morris, T. R., \& Sappington, R. (2017). Sources of self-efficacy and outcome expectations for career exploration and decision-making: A test of the social cognitive model of career self-management. Journal of Vocational Behavior, 99, 107-117.

Loewenberg Ball, D., \& Forzani, F. M. (2009). The work of teaching and the challenge for teacher education. Journal of Teacher Education, 60(5), 497-511. https://doi.org/10.1177/0022487109348479

Mahir, I., Köhler, T., . S., \& PH, S. (2019). Career guidance shortages in Indonesian vocational high school. KnE Social Sciences, 3(12), 223. https://doi.org/10.18502/kss.v3i12.4088

Mitchell, K. E., Al Levin, S., \& Krumboltz, J. D. (1999). Planned happenstance: Constructing unexpected career opportunities. Journal of Counseling \& Development, 77(2), 115-124. https://doi. org/10.1002/j.1556-6676.1999.tb02431.x

Modestino, A. S., Sugiyama, K., \& Ladge, J. (2019). Careers in construction: An examination of the career narratives of young professionals and their emerging career self-concepts. Journal of Vocational Behavior, 115, 1-21. https://doi.org/10.1016/j.jvb.2019.05.003 
Muttaqin, R., Wagimin, W., \& Tadjri, I. (2017). Keefektifan layanan informasi karier berbantuan video interaktif dan live modeling untuk meningkatkan pemahaman karier siswa SMP. Jurnal Bimbingan Konseling, 6(2), 174-179.

Ngadi, N. (2014). Relevansi pendidikan kejuruan terhadap pasar kerja di Kota Salatiga. Jurnal Kependudukan Indonesia, 9(1), 59-70.

Nota, L., Ginevra, M. C., Santilli, S., \& Soresi, S. (2014). Contemporary career construction: The role of career adaptability. In Psycho-social career meta-capacities (pp. 247-263). Springer.

Porfeli, E. J., \& Lee, B. (2012). Career development during childhood and adolescence. New Directions for Youth Development, 134, 11-22. https://doi.org/10.1002/yd.20011

Preston, M. (2018). Pengaruh pola asuh ayah dan ibu terhadap efikasi-diri dalam pengambilan keputusan karier yang dimediasi oleh kepribadian proaktif pada siswa sekolah menengah atas. Universitas Indonesia.

Pryor, R. G., \& Bright, J. E. (2014). The Chaos Theory of Careers (CTC): Ten years on and only just begun. Australian Journal of Career Development, 23(1), 4-12. https://doi.org/10.1177/1038416213518506

Rogers, M. E., \& Creed, P. A. (2011). A longitudinal examination of adolescent career planning and exploration using a social cognitive career theory framework. Journal of Adolescence, 34(1), 163-172.

Santilli, S., Nota, L., \& Hartung, P. J. (2019). Efficacy of a group career construction intervention with early adolescent youth. Journal of Vocational Behavior, 111, 49-58. https://doi.org/10.1016/j.jvb.2018.06.007

Sawitri, D. R. (2008). The influence of the status of identity and self-efficacy of career decisions against the doubts of decision making in first year students at Diponegoro University. Jurnal Psikologi Undip, 5(2), 1-14.

Silvianingsih, S., Degeng, I. N. S., Triyono, T., \& Radjah, C. L. (2019). Utilizing mind-mapping to foster career exploration of high school students. Journal of Educational and Learning Studies, 2(1), 25-30. https://doi. org/10.32698/0462

Sofyan, R., \& Indianti, W. (2019). Pengaruh thinking style tipe II terhadap efikasi diri keputusan karier yang dimediasi oleh planned happenstance skills pada remaja. Jurnal Provitae, 12(2), 41-60.

Stumpf, S. A., Colarelli, S. M., \& Hartman, K. (1983). Development of the Career Exploration Survey (CES). Journal of Vocational Behavior, 22(2), 191-226. https://doi.org/10.1016/0001-8791(83)90028-3

Urbanaviciute, I., Kairys, A., Paradnike, K., \& Pociute, B. (2019). Capturing serendipity in careers: An evaluation of the planned Happenstance Career Inventory with Lithuanian undergraduates. Journal of Career Development, 46(2), 157-170.

Valickas, A., Raišienè, A. G., \& Rapuano, V. (2019). Planned happenstance skills as personal resources for students' psychological wellbeing and academic adjustment. Sustainability, 11(12), 3401.

Wicaksonoputro, H. B., \& Indrayanti, R. (2017). Profil pengangguran dan lama mencari kerja lulusan SMK. Retrieved from https://ldfebui.org/wp-content/uploads/2017/11/BN-10-2017.pdf

Yang, N., Yaung, H., Noh, H., Jang, S. H., \& Lee, B. (2017). The change of planned happenstance skills and its association with career-related variables during school-to-work transition. International Journal for Educational and Vocational Guidance, 17(1), 19-38. https://doi.org/10.1007/s10775-016-9332-z

Zhang, H., \& Huang, H. (2018). Decision-making self-efficacy mediates the peer support-career exploration relationship. Social Behavior and Personality: An International Journal, 46(3), 485-498.

Zikic, J., \& Hall, D. T. (2009). Toward a more complex view of career exploration. The Career Development Quarterly, 58(2), 181-191.

Zikic, J., \& Klehe, U.-C. (2006). Job loss as a blessing in disguise: The role of career exploration and career planning in predicting reemployment quality. Journal of Vocational Behavior, 69(3), 391-409. https://doi. org/10.1016/j.jvb.2006.05.007 